\title{
Dermal Exposure to Hazardous Chemicals in Baby Diapers: A Critical Review of the Quantitative Health Risk Assessment Con-Ducted by the French Agency for Food, Environmental and Occupational Health and Safety (ANSES)
}

\author{
Alfred Bernard
}

\begin{abstract}
Institut de Recherche Expérimentale et Clinique (IREC), Université catholique de Louvain, Belgium ; al-
\end{abstract} fred.bernard@uclouvain.be

Correspondence: alfred.bernard@uclouvain.be; Tel.: +32 476476849

\begin{abstract}
In January 2019, the French Agency for Food, Environmental and Occupational Health and Safety (ANSES) published an opinion on risks related to the presence of hazardous chemicals in infant diapers. ANSES found that health reference values were largely exceeded for polycyclic aromatic hydrocarbons (PAHs), dioxins $(\mathrm{PCCD} / \mathrm{Fs}$ ) and dioxin-like polychlorobiphenyls (DLPCBs). The levels of formaldehyde and of some fragrances were also considered potentially unsafe. Therefore, ANSES concluded that actions have to be taken to restrict levels of these contaminants in diapers. Under the exposure scenario deemed the most reliable by ANSES, estimates of cancer risks of the most potent PAHs detected in diapers exceeded $10^{-3}$ and hazard quotients for neurobehavioral effects attained values up to 66. Regarding dioxins and DL-PCBs, ANSES derived a hazard quotient of 12 for the risk of decreased sperm count at adult age. The aim of this critical review was to examine whether the exposure and risk assessment conducted by ANSES contained potential flaws that could explain such a high exceedance of health reference values. The review will also put into perspective the exposure from diapers with that from breast milk whose benefits for child's health are undisputable despite contamination by PAHs, dioxins and DL-PCBs.
\end{abstract}

Keywords: diaper, dioxin; dioxin-like polychlorobiphenyls; polycyclic aromatic hydrocarbons; formaldehyde; fragrance.

\section{Introduction}

Disposable diapers have improved the quality of life of babies and of their caregivers so much that today having access to diapers has become a basic need. Diapers are made of several layers of materials with different functional properties. The core of diapers contains super-absorbent materials that absorb and retain the urine, keeping the skin dry and clean. Modern diapers offer health benefits by reducing the risks of diaper dermatitis, which is one of the most common skin diseases during infancy. The use of diapers also reduces the risks of skin infection and of enteric pathogen contamination of hands and of the environment [1]. Over the last two decades, there have been significant innovations in the manufacture of baby diapers. Nowadays, diapers are much thinner and much more absorbent than they were in the in the past. These improvements are due to the reduction of wood pulp and the use of sodium polyacrylate, a synthetic strong absorbent that limits the amount of liquid that can migrate from the diaper to the skin of the baby, resulting in a skin rewetting fraction (rewet factor) mostly below 1\% [2]. Another significant change concerns the bleaching of wood pulp, which no more uses elemental chlorine, a possible source of contamination by dioxins [3]. Today, bleaching uses elemental chlorine free or 
total chlorine free methods that prevent the formation of dioxins or dioxin-like compounds [4].

Recently, the safety of disposable baby diapers has been questioned by a report of the French Agency for Food, Environmental, and Occupational Health \& Safety (ANSES). On the basis of chemical concentrations reported by two French laboratories, ANSES conducted a quantitative health risk assessment of various contaminants detected or quantified in disposable diapers [5]. ANSES found that health reference values (HRVs) were exceeded for dioxins (PCCD/Fs), dioxin-like polychlorobiphenyls (DL-PCBs) and polycyclic aromatic hydrocarbons (PAHs). The French agency concluded that long-term health risks cannot be excluded for babies and that regulatory actions have to be taken to ensure the safety of diapers. Therefore, in October 2020, ANSES submitted to the European Chemical Agency (ECHA) a dossier for restricting levels of these hazardous substances in diapers [6]. Of note, excess cancer risk estimates calculated by ANSES were several orders of magnitude above recommended limits while hazard quotients (HQ) attained values higher than 50. Such estimates, if proved to be correct, would be of concern as disposable diapers are used since decades by almost all children in wealthy countries. This paper critically reviews the ANSES risk assessment by examining the accuracy of exposure data and the different assumptions made in risk calculations. The likelihood of health risks will also be assessed by comparing the exposure from diapers with that from breast milk, an important source of dioxins, PAHs and other lipophilic contaminants for breastfed babies.

\section{Materials and Methods}

The risk assessment conducted by ANSES was based on chemical analyses of baby disposable diapers that were performed in 2016, 2017 and 2018 by the French National Institute of Consumption and the Joint Laboratory Service [5]. These laboratories analysed a variety of chemical substances by extracting them with organic solvent or synthetic urine from whole diapers, shredded diapers or shredded parts of diapers (e.g., elastics and sheets). On the basis of these extractions, ANSES adopted three different exposure scenarios and calculated the daily intakes of substances by the dermal route with the following equations:

Scenario 1, extraction with an organic solvent from shredded diapers or shredded parts of diapers:

$$
\mathrm{DI}=\frac{\mathrm{C} \times \mathrm{W} \times \mathrm{N} \times \mathrm{T} \times \mathrm{A}}{\mathrm{bw}}
$$

Scenario 2.1, extraction with synthetic urine from shredded diapers:

$$
\mathrm{DI}=\frac{\mathrm{C} \times \mathrm{W} \times \mathrm{N} \times \mathrm{R} \times \mathrm{A}}{\mathrm{bw}}
$$

Scenario 2.2, extraction with synthetic urine from whole diapers:

$$
\mathrm{DI}=\frac{\mathrm{C} \times W \times \mathrm{N} \times \mathrm{A}}{\mathrm{bw}}
$$

where DI is daily intake ( $\mathrm{pg}, \mu \mathrm{g}$ or $\mathrm{mg} / \mathrm{kg} \mathrm{bw} /$ day); $\mathrm{C}$ is the concentration of the chemical in diaper ( $\mathrm{pg}, \mu \mathrm{g}$ or $\mathrm{mg} / \mathrm{kg}$ ); $\mathrm{W}$ is the weight of the diaper $(\mathrm{kg})$; $\mathrm{N}$ is the number of diapers used per day; $\mathrm{T}$ is the fraction transferred to the skin (\%); $\mathrm{R}$ is the rewet factor $(\%)$; $\mathrm{A}$ is the fraction absorbed by the skin (\%); bw is the body weight of the baby $(\mathrm{kg})$.

The extraction of chemical substances from shredded diapers was performed by sinking at $37^{\circ} \mathrm{C}$ for 4 hours $1 \mathrm{~g}$ of shred in $100 \mathrm{ml}$ of synthetic urine prepared as described by Colón et al. [7]. For the extraction from whole diapers, the diapers were soaked three times with $200 \mathrm{ml}$ of synthetic urine at 15 minutes interval. Diapers were then placed in an oven at $37^{\circ} \mathrm{C}$ during 16 hours. Between 220 and $250 \mathrm{ml}$ of synthetic urine were recovered. A total of 19 diapers from different brands were tested according to these procedures. The procedures for the extraction with organic solvent were not described in the ANSES report for confidentiality reasons [5].

Like in a previous study on diapers and tampons [3], ANSES performed first a screening level estimate by applying a worst-case scenario to all substances quantified or 
detected in diapers. Then, for substances exceeding levels of concern, a refined assessment was conducted for every 6 months-period of age of the infant by incorporating more realistic assumptions for the skin transfer under scenario 1 ( $\mathrm{T}$ value of $7 \%$ instead of $100 \%$ ) and for the rewet factor under scenario 2.1 ( $R$ value of $1.32 \%$ instead of $100 \%$ ). This refined analysis showed that as expected health risks were highest in youngest infants aged 0-6 months. The present review will therefore focus on this period of age for which exposure parameters selected by ANSES were a body weight of $3.9 \mathrm{~kg}$, a diaper weight of $0.024 \mathrm{~kg}$ and the use of 7.98 diapers per day.

ANSES based its risk assessment on the scenario 2.2 deemed the most reliable by the French agency. The European Disposables and Nonwovens Association (EDANA) considers, however, that a realistic scenario should include an appropriate rewet factor [4]. For purpose of comparison, this review will assess health risks of diapers by using the equation of scenario 2.1 with a rewet factor of $1 \%$ to all substances detected or quantified by ANSES in the organic solvent or synthetic urine extracts of shredded or whole diapers. This rewet factor a $1 \%$ is conservative since in the study of Dey et al. [2] the proportion of urine resurfacing back to the top sheet under pressure averaged $0.46 \%$ with a range of $0.32-0.66 \%$. As done by ANSES, a skin absorption of $100 \%$ was assumed for lipophilic substances such as PAHs, dioxins and DL-PCBs. For chemicals known to be poorly absorbed by the skin, fractional absorption data derived in vivo or in vitro for human skin or non-human primate skin will be used.

For substances with a threshold effect, ANSES estimated health risks by calculating the hazard quotient, which is the ratio of the daily intake to the tolerable daily intake as follows:

$$
\mathrm{HQ}=\underline{\mathrm{DI}}
$$

TDI

where HQ is the hazard quotient; DI is the daily intake and TDI is the tolerable daily intake, both expressed in $\mathrm{pg}, \mu \mathrm{g}$ or $\mathrm{mg} / \mathrm{kg}$ body weight.

For substances assumed to have no-threshold effects (PAHs), ANSES estimated the excess cancer risk using the following equation:

$$
\mathrm{ECR}=\frac{\mathrm{DI} \times \mathrm{CSF} \times \mathrm{T} \times \mathrm{ADAF}}{70}
$$

where ECR is the excess cancer risk; DI is the daily intake ( $\mu \mathrm{g} / \mathrm{kg}$ bw/day); CSF is the cancer slope factor $(\mu \mathrm{g} / \mathrm{kg} / \text { day) })^{-1}$; $\mathrm{T}$ is the duration of exposure (years); 70 is the duration of lifetime conventionally set at 70 years, and ADAF is the age-adjustment factor set at default values of 10 for the age group $0-<2$ years and of 3 for the age group $2-<16$ years [8].

This review also calculated the excess skin cancer risk of PAHs using a dermal CSF of $3.5\left(\mu \mathrm{g} / \mathrm{cm}^{2} / \mathrm{day}\right)^{-1}$ [9] and assuming a skin surface area in contact with the diaper of 234 $\mathrm{cm}^{2}[10,11]$. In order to consolidate the cancer risk assessment of PAHs, this paper will also calculate the margin of exposure (MOE) of PAHs from diapers by the same approach as that followed by EFSA for food products [12].

The largest number of detected or quantified substances was found in organic solvent extracts of shredded diapers. This includes: volatile organic compounds (naphthalene, styrene, toluene, 1,2,3-chlorobenzenes, p-isopropyl toluene, xylenes, chlorobenzene), pesticides (hexachlorobenzene, quintozene and its metabolite pentachloroaniline, glyphosate and its metabolite AMPA), formaldehyde, PCDD/Fs, DL-PCBs and perfumes (benzyl alcohol, benzyl salicylate, coumarin, hydroxyisohexyl 3-cyclohexene carboxaldehyde (Lyral®), butylphenyl methylpropional (Lilial®), limonene, linalol, alpha-isomethyl ionone). In organic solvent extracts of shredded parts of diapers, only PCDD/Fs and PAHs were found. The substances detected or quantified in simulated urine extracts of shredded or whole diapers were PCDD/Fs, DL-PCBs, PAHs and formaldehyde.

The present review will concentrate on PAHs, PCCD/Fs and DL-PCBs for which HRVs in the ANSES report (HQ of 1 and ECR of $10^{-6}$ ) were exceeded in all age groups of children. The review will also address substances for which HRVs were exceeded only during the first year of life or for which there was a risk of HRVs exceedance when 
aggregating intake from diapers with that from other potential sources of exposure. In the ANSES report, this included hexachlorobenzene, 1,2,3-trichlorobenzene, 1,2,4-trichlorobenzene, formaldehyde, hexachlorobenzene, 1,2,4-trichlorobenzene and all detected fragrances.

\section{Dioxins and dioxin-like PCBs}

\subsection{Concentrations in diapers}

Three PCDDs congeners and six PCDFs congeners were found in diapers in detectable or quantifiable concentrations. The two most potent dioxins, TCDD and 1,2,3,7,8-pentachlorodibenzo-p-dioxin, were not detected. Almost all DL-PCBs congeners were detected or quantified. Table 1 shows the TEQ concentrations of PCDD/Fs, DL-PCBs and of the sum of PCDD/Fs and DL-PCBs (total TEQ) in diapers under the different extraction scenarios. There are several intriguing observations in these results that deserve further investigation. First, the TEQ concentrations are, if not similar, much greater (under scenario 2.1) than those reported 30 years ago when diapers were suspected of being bleached with elemental chlorine and when also background environmental levels of PCDD/Fs and DL-PCBs were much higher [3]. Surprisingly also, TEQ concentrations did not differ between the extracts with organic solvent and that with synthetic urine despite the fact that PCDD/Fs and PCBs are notoriously insoluble in water. By contrast, the patterns of congeners were sharply different between the two modes of extraction. In the organic solvent extract of diapers, PCCD/Fs and DL-PCBs almost equally contributed to total TEQ, which is frequently the case in environmental or biological matrices [13]. Rather, in the extracts with synthetic urine, DL-PCBs accounted for almost $90 \%$ of total TEQ in whole diapers whereas they contributed to only $10 \%$ of total TEQ in shredded diapers. It is unclear why the proportions of PCDD/Fs and DL-PCBs are inverted when extracting them under the same conditions from shredded or from whole diapers. These illogical and atypical findings unavoidably raise questions about the accuracy of PCCD/Fs and DLPCBs exposure data used by ANSES. Contrary to common practice, TEQ concentrations of PCDDs and PCDFs were not reported separately but from the list of detected or quantified congeners given in the ANSES report [5], it can be deduced that PCDFs accounted for more than $50 \%$ of PCDD/Fs-TEQ. ANSES, however, provided separately the concentrations of PCB 126, which accounted for almost $90 \%$ of DL-PCBs-TEQ.

Table 1. Risk assessment of dioxins (PCDD/Fs) and DL-PCBs in diapers conducted by ANSES and comparison of the intake from diapers with that from breast milk

\begin{tabular}{|c|c|c|c|c|c|c|c|}
\hline $\begin{array}{c}\text { ANSES } \\
\text { extraction } \\
\text { scenario }\end{array}$ & Compound & $\begin{array}{l}\text { Cooncentration } \\
\text { in diaper } \\
(\mathrm{pg} \mathrm{TEQ} / \mathrm{kg})^{1}\end{array}$ & $\begin{array}{c}\text { Intake from } \\
\text { diaper } \\
(\mathrm{pg} \mathrm{TEQ} / \mathrm{kg} / \mathrm{d})^{2}\end{array}$ & $\begin{array}{c}\text { EFSA TDI } \\
\text { (pg TEQ/kg/d) }\end{array}$ & $\begin{array}{l}\text { Hazard } \\
\text { quotient }\end{array}$ & $\begin{array}{c}\text { Intake from } \\
\text { breast milk } \\
(\mathrm{pg} \mathrm{TEQ} / \mathrm{kg} / \mathrm{d})^{3}\end{array}$ & $\begin{array}{c}\text { Intake ratio } \\
\text { breast milk/diaper }\end{array}$ \\
\hline Scenario 1 & $\mathrm{PCDD} / \mathrm{Fs}$ & 39.8 & 0.14 & \multirow{3}{*}{0.3} & 0.47 & 12.2 & 87.1 \\
\hline Organic solvent & DL-PCBs & 43.4 & 0.15 & & 0.49 & 9.55 & 63.7 \\
\hline Shredded diaper & PCDD/Fs + DL-PCBs & 83.2 & 0.29 & & 0.96 & 21.7 & 74.8 \\
\hline Scenario 2.1 & $\mathrm{PCDD} / \mathrm{Fs}$ & 92.0 & 0.0596 & \multirow{3}{*}{0.3} & 0.20 & 12.2 & 205 \\
\hline Synthetic urine & DL-PCBs & 7.55 & 0.0049 & & 0.02 & 9.55 & 1,953 \\
\hline Shredded diaper & PCDD/Fs + DL-PCBs & 99.6 & 0.0645 & & 0.22 & 21.7 & 336 \\
\hline Scenario 2.2 & $\mathrm{PCDD} / \mathrm{Fs}$ & 8.84 & 0.43 & \multirow{3}{*}{0.3} & 1.45 & 12.2 & 28.4 \\
\hline Synthetic urine & DL-PCBs & 63.6 & 3.12 & & 10.4 & 9.55 & 3.06 \\
\hline Whole diaper & PCDD/Fs + DL-PCBs & 72.4 & 3.55 & & 11.9 & 21.8 & 6.14 \\
\hline
\end{tabular}

${ }^{1}$ TEQ concentrations based on $\mathrm{WHO}_{2005}$ TEF values.

${ }^{2}$ Intake from diaper was calculated for an infant aged 0-6 months (body weight, $3.9 \mathrm{~kg} ; 7.98$ diapers/day; diaper weight, $24 \mathrm{~g}$ ). 
${ }^{3}$ Intake from breast milk was based on the data of [14] that were adapted to the year of 2017 on the basis of an annual decline of $10 \%$ [15]. The PCDD/Fs and DL-PCBs daily intake were estimated for an infant of $5 \mathrm{~kg}$ of body weight fed daily with $700 \mathrm{ml}$ of breast milk containing $25 \mathrm{~g} / \mathrm{l}$ of lipids.

\subsection{Toxicokinetics}

Because of their lipophilicity, dioxins and DL-PCBs are usually well absorbed by all routes of exposure [16,17]. The fractional oral absorption of dioxins and DL-PCBs varies between approximately 50 and $100 \%$ depending on the ingested dose, the duration of exposure and the degree of chlorination, the lower chlorinated congeners being better absorbed than the higher chlorinated ones. In vivo studies in animals indicate similarly high fractional dermal absorption in the range of $40-60 \%$ depending on the dose and duration of exposure. In vitro studies with human skin suggest, however, that the dermal absorption would be less important, especially in matrices such as soil or textiles [16,17]. Because wood pulp used in the absorbent core of diapers is a mixture of organic fibres, it is likely that dioxins are strongly bound to these fibres and therefore not readily absorbed. For this reason, De Vito and Schecter [3] assumed a fractional dermal absorption of 3\% for dioxins from diapers, a value that they considered conservative. Once absorbed, dioxins are readily distributed to all organs and over time they accumulate in liver and adipose tissue. The metabolism of dioxins and DL-PCBs is extremely slow, the higher chlorinated congeners being particular resistant to xenobiotics-metabolizing enzymes. The main routes of excretion are via the bile and faeces. Human milk is an additional important route of excretion since the TEQ concentrations of PCDD/Fs and DL-PCBs are approximately the same in the lipid fraction of all tissues and body fluids, including milk. During lactation, the body burden of the mother decreases as a result of the dioxin transfer to the nursing child [18]. The half-life of dioxins greatly varies with the degree of chlorination but also with the age, ranging from less than one year in infants up to 30 years in old adults $[16,17,19]$.

\subsection{Critical adverse effects}

Two basic concepts underly the risk assessment of dioxins and DL-PCBs. The first concept is that all toxic effects of dioxins and DL-PCBs are mediated by the sustained activation of the intracellular aryl hydrocarbon receptor (AhR). The effects of individual congeners are assumed to be additive after adjustment for their potency to activate the AhR. This adjustment is made using toxic equivalency factors (TEF) established relatively to TCDD, the most potent congener. Recent studies, however, have revealed large between-species differences in the potency of dioxins and PCBs congeners to activate the AhR. For instance, while the relative effective potencies (REP) of PCBs 126, 118 and 156 derived from rat lung cells are in a good accordance with the $\mathrm{WHO}_{2005} \mathrm{TEF}$, tested on human lung cells PCB 126 elicited a 10 to 100 -fold lower AhR-mediated activity while PCB 118 and PCB 156 were almost inactive [20]. There is thus clearly a need to develop humanspecific REP/TEF based on toxicologically relevant endpoints [21,22]. The second important concept in dioxins and DL-PCBs toxicology is the body burden concept assuming that whatever the duration of exposure and the adverse outcome, risks are determined by the amount of dioxins and DL-PCBs accumulated in the body over time. In case of acute exposure, as in the Seveso accident, there is nevertheless some uncertainty regarding the respective influence of the peak exposure and of the chronic exposure in the years following the accident [23].

Dioxins and DL-PCBs are non-genotoxic carcinogens, which above a certain threshold promote cancer development at various sites including the skin, the ovaries and the liver. TCDD, 2,3,4,7,8-PCDF, PCB 126 and DL-PCBs have been classified by IARC as human carcinogens [24]. Dioxins and DL-PCBs also exert a wide range of non-carcinogenic effects including cutaneous, hepatic, neurological, immunological, reproductive, endocrine and developmental effects. Of these, the effects on male fertility and on the thyroid function during childhood exposure are regarded as the most critical. 
Recently, EFSA derived a tolerable weekly intake (TWI) of $2 \mathrm{pg} T E Q / \mathrm{kg}$ bw on the basis of the chronic Russian Children's Study, showing that peripubertal serum TCDD and PCDDs-TEQ were associated with lower sperm concentration, total sperm count and total motile sperm count measured 10 years later in healthy young men $[13,25]$. It should be noted that in this Russian study, there were no independent associations between semen parameters and serum levels of PCDFs-TEQ, DL-PCBs-TEQ or total TEQ. According to the authors, this suggests that the association of dioxins with decreased male fertility might be specific to PCDD-TEQ [25]. According to the EFSA's expert panel, the lack of associations with PCDFs-TEQ and DL-PCBs-TEQ in the Russian study might be explained by the much lower AhR-activating potency of some congeners of dioxins and DL-PCBs [13]. Recently, indeed, Strapácová et al. [20] found that human lung REP for 2,3,4,7,8-pentachlorodibenzofuran and PCB 126 were 10 to 100 times lower than the respective rat lung REP at the basis of the current $\mathrm{WHO}_{2005}$ TEF values. This inevitably has implications for risk assessment as PCB 126 is the DL-PCB congener contributing the most to DL-PCBsTEQ. PCB 126 also contributes to about one third of total TEQ activity in human biological samples, including the serum of boys in the Russian study. EPA derived a slightly higher oral reference dose (RfD) of $0.7 \mathrm{pg} / \mathrm{kg} / \mathrm{day}$ for TCDD on the basis of the Seveso study by Mocarelli et al. [26] reporting decreased sperm concentrations and decreased motile sperm counts in men acutely exposed to TCDD at the time of the Seveso accident [23]. For assessing health risks of mixtures of PCCD/Fs and DL-PCBs, both EFSA and EPA recommend the use of TEF values.

No regulatory body has so far established HRVs for TCDD by the inhalation or the dermal route of exposure. In contrast to PAHs (see below), there is some reason to believe that dermal exposure to dioxins and DL-PCBs might cause similar systemic effects as oral exposure, which may legitimate the dermal-oral route extrapolation made in the ANSES report. A variety of systemic effects have indeed been observed in mice following repeated dermal exposures to dioxins including conjunctiva inflammation, fibrosarcoma, thymus atrophy, liver fatty degeneration and bronchiolar adenomatoid changes [16,17].

It should be noted that ANSES initially based its risk assessment of dioxins and DLPCBs on the RfD of EPA, presumably for purpose of consistency as ANSES also adopted the HRVs of EPA for assessing risks of PAHs [5]. However, in its restriction proposal, ANSES decided to calculate the concentration limit of dioxins and DL-PCBs in diapers using the TDI established by EFSA [6]. The present review took into account this latest position of ANSES and recalculated the HQ values of dioxins and DL-PCBs on basis of the TDI of EFSA.

\subsection{Evaluation}

Table 1 shows the risk estimates made by ANSES for PCDD/Fs, DL-PCBs and the sum of PCDD/Fs and DL-PCBs (total TEQ) under the different extraction scenarios. Under the scenario 2.2, the most reliable according to ANSES, the hazard quotient (HQ) for total TEQ reached a value of 11.8 while for the two other scenarios it remained below 1 . Scenario 2.2 is based on the assumption that all the PCDD/Fs and DL-PCBs in diapers reach the baby skin (no application of the rewet factor) and are entirely absorbed, resulting in a systemic bioavailability of $100 \%$ for the total TEQ content of diapers. Such a very conservative assumption is likely to greatly over-estimate the intake as modern diapers are precisely designed to retain a maximum of urine. If one adopts a more realistic assessment accounting for the rewet factor of $1 \%$ recommended by Dey et al. [2], Table 2 shows that all HQ values under scenario 2.2 fall below 1 . 
Table 2. Risk assessment of dioxins (PCDD/Fs) and DL-PCBs in diapers with the scenario 2.1 equation incorporating a rewet factor of $1 \%$ and comparison of the intake from diapers with that from breast milk.

\begin{tabular}{|c|c|c|c|c|c|c|c|}
\hline $\begin{array}{c}\text { ANSES } \\
\text { extraction } \\
\text { scenario }\end{array}$ & Compound & $\begin{array}{c}\text { Cooncentration in } \\
\text { diaper } \\
(\mathrm{pg} \mathrm{TEQ} / \mathrm{kg})^{1}\end{array}$ & $\begin{array}{c}\text { Intake from } \\
\text { diaper } \\
(\mathrm{pg} \mathrm{TEQ} / \mathrm{kg} / \mathrm{d})^{2}\end{array}$ & $\begin{array}{c}\text { EFSA TDI } \\
(\mathrm{pg} \text { TEQ/kg/d) }\end{array}$ & $\begin{array}{l}\text { Hazard } \\
\text { quotient }\end{array}$ & $\begin{array}{c}\text { Intake from } \\
\text { breast milk } \\
(\mathrm{pg} \mathrm{TEQ} / \mathrm{kg} / \mathrm{d})^{3}\end{array}$ & $\begin{array}{c}\text { Intake ratio } \\
\text { breast milk/diaper }\end{array}$ \\
\hline Scenario 1 & $\mathrm{PCDD} / \mathrm{Fs}$ & 39.8 & 0.020 & & 0.065 & 12.2 & 626 \\
\hline Organic solvent & DL-PCBs & 43.4 & 0.021 & & 0.070 & 9.55 & 448 \\
\hline Shredded diaper & $\mathrm{PCDD} / \mathrm{Fs}+\mathrm{DL}-\mathrm{PCBs}$ & 83.2 & 0.041 & & 0.135 & 21.7 & 531 \\
\hline Scenario 2.1 & $\mathrm{PCDD} / \mathrm{Fs}$ & 92.0 & 0.045 & & 0.152 & 12.2 & 270 \\
\hline Synthetic urine & DL-PCBs & 7.55 & 0.0037 & 0.3 & 0.012 & 9.55 & 2,574 \\
\hline Shredded diaper & PCDD/Fs + DL-PCBs & 99.6 & 0.049 & & 0.163 & 21.7 & 444 \\
\hline Scenario 2.2 & $\mathrm{PCDD} / \mathrm{Fs}$ & 8.84 & 0.0043 & & 0.014 & 12.2 & 2,811 \\
\hline Synthetic urine & DL-PCBs & 63.6 & 0.031 & & 0.105 & 9.55 & 306 \\
\hline Whole diaper & PCDD/Fs + DL-PCBs & 72.4 & 0.036 & & 0.119 & 21.8 & 612 \\
\hline
\end{tabular}

${ }^{1} \mathrm{TEQ}$ concentrations based on $\mathrm{WHO}_{2005}$ TEF values.

${ }^{2}$ Intake from diaper was calculated for an infant aged 0-6 months (body weight, $3.9 \mathrm{~kg} ; 7.98$ diapers/day; diaper weight, $24 \mathrm{~g}$ ).

${ }^{3}$ Intake from breast milk was based on the data of [14] that were adapted to the year of 2017 on the basis of an annual decline of $10 \%$ [15]. The PCDD/Fs and DL-PCBs daily intake were estimated for an infant of $5 \mathrm{~kg}$ of body weight fed daily with $700 \mathrm{ml}$ of breast milk containing $25 \mathrm{~g} / \mathrm{l}$ of lipids.

But even though the systemic bioavailability of dioxins and DL-PCBs would be 100\%, HQ estimates by ANSES remain questionable in light of observations in the Russian study, in which the decreased sperm count correlated only with PCDDs-TEQ [25]. If as suggested by the authors, the association with sperm count is specific of PCDDs, then the HQ should be calculated with PCDDs-TEQ only, which would decrease the HQ to approximately 0.7 under scenario 2.2 (PCDFs account for less than 50\% of PCDD/Fs-TEQ, see concentrations in diapers above). Alternatively, if as suggested by the EFSA expert panel [13], the lack of correlation with DL-PCBs is due to the 10 to 100 -fold lower potency of DL-PCBs to activate the AhR of human cells as compared to rat cells, then under scenario 2.2, HQ values fall below 1 in Table 1 and even below 0.01 in Table 2 when incorporating the rewet factor of $1 \%$.

The overestimation of dioxins and DL-PCBs risks in the ANSES report is supported by the comparison of the intake from diapers with that from breast milk. As shown in Table 1, dietary intakes of total TEQ by nursing infants are 74.8, 336 and 6.1 times greater than the daily intakes from diapers under the extraction scenarios 1, 2.1 and 2.2, respectively. These figures were based on the concentrations of dioxins and DL-PCBs in human milk measured in France in 2010 [16]. In order not to bias the comparison by the downwards temporal trends of dioxin exposure, these concentrations were adjusted to the year 2017 by assuming for most recent years an annual decline of 10\% [15]. Similar human milk/diaper intake ratios were found with milk samples analysed in nine European countries in 2014-2015 [13]. These ratios ranged from 58 to 116, 261 to 528 and 4.8 to 9.5 under the ANSES extraction scenarios 1, 2.1 and 2.2, respectively. As shown in Table 2, the total TEQs intake by nursing infants are more than 400 times greater than the intake from diapers under the three ANSES scenarios when the latter are calculated by incorporating the rewet factor of $1 \%$. These calculations make unrealistic the assumption by ANSES that diapers contribute to $10 \%$ of the total TEQ intake [6]. It is also interesting to compare concentrations in human milk with the concentration limit proposed by ANSES in its restriction proposal [6]. ANSES recommends a maximal concentration for total TEQ in diapers of $0.7 \mathrm{pg} / \mathrm{kg}$ diaper. This TEQ concentration is 171 to 342 times lower than the concentrations in human milk observed in 2014-2015 in nine European countries (range, 120$240 \mathrm{pg}$ TEQ/kg) [13]. 
There is no evidence that at current exposure levels in the European Union dioxins and DL-PCBs in breast milk reduce the future fertility of breastfed boys. On the contrary, in a study conducted among adolescents, breastfeeding was associated in a dose-dependent manner with an increase of serum inhibin B, a marker of fertility at adult age that was measured with two different immunoassays [27]. The increase averaged $20 \%$ in adolescents who were breastfed for more than six months. The lack of adverse effects of breastfeeding on male fertility despite the relatively high concentrations of dioxins and DLPCBs in breast milk might be explained by the short half-lives of these contaminants during early life, which coupled with the child's rapid growth prevents an excessive increase of the dioxin body burden $[16,17,19]$. In the Seveso cohort acutely exposed to TCDD, a decrease of sperm count was found in men who had been breastfed in the years following the accident. Mothers of children with decreased sperm count had however a median serum level of TCDD of $58.9 \mathrm{pg} / \mathrm{g}$ fat, which was approximately 10 times higher than the TCDD background serum levels in the 1970s and which is more than 50 times higher than current levels of TCDD in serum and breast milk [26]. Concentrations of dioxins and DLPCBs in breast milk have considerably decreased over the last fifty years, with on average an annual decrease of $6 \%$ between 1972 and 2011 according to a Swedish study [15]. This temporal trend parallels the decline of sperm count in western countries, which has been estimated at 1.4\% per year between 1973 and 2011 [28]. These parallel downwards temporal trends of human dioxin exposure and sperm count, argue against the hypothesis implicating dioxins as a significant driver of the global decline of western men fertility. These temporal trends also make unrealistic the risk of decreased male fertility calculated by ANSES for dioxins in diapers, which contribute to infant exposure more than 100 times less than breast milk. The possibility of nonmonotonic relationships could be invoked to causally link these parallel downwards trends but this would not be consistent with the dose-dependent decrease of sperm count with increasing dioxin exposure observed in the Russian study [25].

\section{Polycyclic aromatic hydrocarbons (PAHs)}

\subsection{Concentrations in diapers}

As shown in Table 3, concentrations of PAHs in diapers in the ANSES report ranged from 249 to $598 \mu \mathrm{g} / \mathrm{kg}$ [5]. These concentrations actually were not quantified but correspond to the half of the limits of quantification (LOQ) of individual PAHs. The analytical method used by French laboratories had indeed a relatively poor sensitivity with limits of detection (LOD) of individual PAHs higher than $150 \mu \mathrm{g} / \mathrm{kg}$. Actually, this LOD is two orders of magnitude higher than the LODs of methods recommended to measure PAHs in foodstuffs [13]. This surrogate method for evaluating exposure explains the atypical concentration pattern of PAHs in diapers showing little variation between individual PAHs while in most environmental or biological matrices individual PAHs concentrations differ by a factor of 10 to 100 . Under these conditions, it is puzzling that ANSES recommends a concentration limit as low as $2.7 \mathrm{ng}$ TEQ/kg diaper for the sum of PAHs [6]. In the case of benzo[a]pyrene and dibenz[a,h]anthracene (TEF of 1), this concentration limit is five orders of magnitude lower than the LOD of the analytical method used in the ANSES risk assessment. This concentration limit for diapers is even 10 times lower than the median LOD of methods used to measure PAHs in food products [13]. 
Table 3. Risk assessment of dioxins (PCDD/Fs) and DL-PCBs in diapers with the scenario 2.2 equation and comparison of the intake from diapers with that from breast milk.

\begin{tabular}{|c|c|c|c|c|c|c|c|c|c|c|}
\hline HAPs & $\begin{array}{l}\text { Concentration } \\
(\propto \mathrm{g} / \mathrm{kg})^{1}\end{array}$ & $\begin{array}{c}\text { Intake } \\
\text { from diaper } \\
(\circ \mathrm{g} / \mathrm{kg} / \mathrm{d})^{2}\end{array}$ & $\mathrm{TEF}^{3}$ & $\begin{array}{c}\text { Intake from } \\
\text { diaper } \\
(\circ g \mathrm{TEQ} / \mathrm{kg} / \mathrm{d})^{2}\end{array}$ & $\begin{array}{c}\text { EPA } \\
\text { oral RfD. } \\
(\propto g / k g / d)\end{array}$ & $\begin{array}{c}\text { Hazard } \\
\text { quotient }\end{array}$ & $\begin{array}{c}\text { EPA } \\
\text { oral CSF } \\
(\mathrm{mg} / \mathrm{kg} / \mathrm{d})\end{array}$ & $\begin{array}{c}\text { Excesss } \\
\text { cancer risk }\end{array}$ & $\begin{array}{l}\text { Intake from } \\
\text { breast milk } \\
(\circ \mathrm{g} / \mathrm{kg} / \mathrm{d})^{4}\end{array}$ & $\begin{array}{c}\text { Intake ratio } \\
\text { breast } \\
\text { milk/diaper }\end{array}$ \\
\hline Cyclopenta[c,d]pyrene & 311 & 15.3 & 0.1 & 1.53 & & 5.51 & & $1.09 \times 10^{-4}$ & & \\
\hline Chrysene & 249 & 12.2 & 0.01 & 0.12 & & 0.41 & & $8.76 \times 10^{-6}$ & 0.12 & $9.8 \times 10^{-3}$ \\
\hline 5-methylchrysene & 311 & 15.3 & 0.01 & 0.15 & & 0.51 & & $1.09 \times 10^{-5}$ & & \\
\hline Benzo[b]fluoranthene & 381 & 18.7 & 0.1 & 1.87 & & 6.24 & & $1.34 \times 10^{-4}$ & 0.11 & $5.9 \times 10^{-3}$ \\
\hline Benzo[k]fluoranthene & 369 & 18.1 & 0.1 & 1.81 & & 6.03 & & $1.29 \times 10^{-4}$ & 0.88 & $4.9 \times 10^{-2}$ \\
\hline Benzo[j]fluoranthene & 369 & 18.1 & 0.1 & 1.81 & 0.3 & 6.03 & 1 & $1.29 \times 10^{-4}$ & & \\
\hline Benzo[e]pyrene & 598 & 29.4 & 0.01 & 0.29 & & 0.98 & & $2.10 \times 10^{-5}$ & & \\
\hline Benzo[a]pyrene & 405 & 19.9 & 1 & 19.9 & & 66.3 & & $1.42 \times 10^{-3}$ & 0.11 & $5.5 \times 10^{-3}$ \\
\hline Dibenzo[a,h]anthracene & 311 & 15.3 & 1 & 15.3 & & 51.0 & & $1.09 \times 10^{-3}$ & 0.61 & $4.0 \times 10^{-3}$ \\
\hline Benzo[g,h,i]perylene & 418 & 20.5 & 0.01 & 0.21 & & 0.68 & & $1.47 \times 10^{-5}$ & 0.73 & $3.6 \times 10^{-3}$ \\
\hline PAHs & 3,722 & 182 & & 33.8 & & 113 & & $2.41 \times 10^{-3}$ & 2.56 & $1.4 \times 10^{-2}$ \\
\hline 8PAHs & 2,133 & 104 & & & & & & & 2.56 & $2.5 \times 10^{-2}$ \\
\hline 4PAHs & 1,035 & 50.8 & & & & & & & 0.34 & $6.7 \times 10^{-3}$ \\
\hline
\end{tabular}

${ }^{1}$ Extraction from whole diaper with synthetic urine.

${ }^{2}$ Intake from diaper was calculated according to the ANSES scenario 2.2 for an infant aged 0-6 months (body weight, $3.9 \mathrm{~kg}$; 7.98 diapers/day; diaper weight, $24 \mathrm{~g}$ ) by assuming a fractional dermal and oral absorption of $100 \%$.

${ }^{3}$ TEF values proposed by INERIS [29].

${ }^{4}$ Intake from breast milk was based on the data of Santonicola et al. [30] and calculated for an infant of $5 \mathrm{~kg}$ of body weight fed daily with $700 \mathrm{ml}$ of maternal milk containing $25 \mathrm{~g} / \mathrm{l}$ of lipids.

No study could be identified in the peer-reviewed literature to compare the PAHs concentrations in diapers used by ANSES with those from other sources. In 2019, however, the Federal Food Safety and Veterinary Office in Switzerland conducted a survey of PAHs in diapers using, after some modifications, an analytical method that can correctly quantify PAHs in food samples [31]. The concentrations of PAHs measured in the absorbent core of five brands of diapers ranged from $<0.15$ to $4.6 \mu \mathrm{g} / \mathrm{kg}$ and the concentrations of the two most potent PAHs, benzo[a]pyrene and dibenz[a,h]anthracene, ranged from $<0.12$ to $1.4 \mu \mathrm{g} / \mathrm{kg}$. Similar low concentrations were found in the non-absorbent parts of the diapers, the most potent PAHs being even undetectable in most cases. Values reported in the Swiss report are thus two to three orders of magnitude lower than those at the basis of the quantitative health risk assessment performed by ANSES.

\subsection{Toxicokinetics}

PAHs are lipophilic substances that are usually well absorbed by all routes $[32,33]$. The dermal absorption varies between species, the anatomic site, the solvent or vehicle and the type of experimental study (in vivo or ex-vivo). Human studies testing PAHs in organic solvent have reported fraction dermal absorption up to $80 \%$ but it is likely that the skin absorption of PAHs is enhanced by the use of an organic solvent. The fractional dermal absorption of PAHs can reasonably be assumed to be in the range of $10 \%$ to $60 \%$. Absorbed PAHs are distributed in the whole body and especially in lipid rich organs. In the skin, like in internal organs, PAHs are rapidly metabolized by cytochrome P-450 dependent enzymes into water soluble compounds, which can be further transformed into conjugates. The metabolism of PAHs involves the formation of electrophilic intermediates that can bind to DNA and initiate tumours. PAHs metabolites and their conjugates are eliminated via the urine and faeces with short half-lives. Like for dioxins, breastfeeding is an additional route of excretion [32,33]. 


\subsection{Critical adverse effects}

\subsubsection{Carcinogenic effects}

Data on the carcinogenicity of PAHs in humans essentially derive from studies among workers with high inhalation or dermal exposure to mixtures of PAHs. There are no adequate carcinogenicity data for human exposure by ingestion. In contrast, there is ample evidence of increased risks of lung cancer in occupations involving exposure to PAHs mixtures containing benzo[a]pyrene such as aluminium production, chimney sweeping, coal gasification, coal-tar distillation, coke production, iron and steel founding, and paving and roofing with coal tar pitch. All these occupational exposures are classified as carcinogenic to humans. In industry, an increased risk of skin cancer (including the scrotum) has been documented following high dermal exposure to mixtures of PAHs including benzo[a]pyrene, such as soot, coal tar, shale oils, coal tar pitches and unrefined mineral oils [34].

In animals, like in humans, the sites of tumours induced by PAHs are largely determined by the route of exposure. By inhalation or intra-tracheal administration, benzo[a]pyrene induces only respiratory tract cancers. Upper digestive tract tumours were observed in some inhalation studies but this is most probably the consequence of the muco-ciliary clearance of inhaled PAHs. In chronic oral bioassays, benzo[a]pyrene induces mainly tumours of the digestive tract (forestomach, oesophagus, tongue, larynx, liver). By the dermal route, lifetime carcinogenicity bioassays in several strains of mice have demonstrated that benzo[a]pyrene induces only skin tumours. These studies involved 2- or 3-times/week exposure protocols, at least two exposure levels plus controls, and histopathological examinations of the skin and internal organs (for review see [34, 35]. As there is no experimental evidence suggesting dermally applied PAHs may increase the risk of systemic tumours, logically thus, skin cancer should be considered as the critical effect for the dermal exposure to PAHs. The lack of systemic carcinogenicity of PAHs applied to the skin, even at very high doses, can be explained by the rapid metabolism of PAHs in the skin. A recent study using a realistic human ex-vivo skin model has shown that less than $3 \%$ of benzo[a]pyrene applied to the skin is bioavailable in the unmetabolized form, the only form susceptible to initiate cancer systemically [35]. This percentage might still be over-estimated as one can expect that ex-vivo human skin has a lower metabolic activity than in vivo. Benzo[a]pyrene is a complete carcinogen acting as both an initiator and a promoter of carcinogenesis. The mechanism by which benzo[a]pyrene induces carcinogenicity is through its mutagenicity, a mechanism that presumably applies to all types of tumours, regardless the route of exposure [34].

EPA established a cancer slope factor (CSF) of $1(\mathrm{mg} / \mathrm{kg} / \text { day })^{-1}$ for assessing human cancer risk associated with lifetime oral exposure to benzo[a]pyrene [34]. This CSF was derived from the digestive tract tumours observed in mice. In addition, for the assessment of cancer risks during early life, EPA recommends the application of an age-dependent adjustment factor (ADAF) to account for the fact that benzo[a]pyrene is a genotoxic carcinogen and also that the CSF was based on carcinogenic effects observed in adult animals.

\subsubsection{Developmental effects}

Animal studies demonstrate that exposure to benzo[a]pyrene is associated with developmental (including neurotoxic), reproductive and immunological effects. In addition, epidemiological studies involving exposure to PAHs mixtures have reported associations between biomarkers of benzo[a]pyrene exposure (benzo[a]pyrene diol epoxide-DNA adducts) and adverse birth outcomes, neurobehavioral effects and decreased fertility. These adverse effects in humans and animals have been demonstrated by inhalation or oral exposures to benzo[a]pyrene. EPA established an oral RfD of benzo[a]pyrene of 0.3 $\mu \mathrm{g} / \mathrm{kg} /$ day on the basis of neurobehavioral changes in rats exposed to benzo[a]pyrene during early life [32]. 


\subsection{Evaluation}

PAHs are a family of toxicants that are ubiquitous in the environment. These contaminants are of concern because several PAHs congeners are highly carcinogenic in laboratory animals and have been long recognized as potent human carcinogens, causing lung cancer by inhalation and skin cancer by dermal exposure. Table 3 based on the data from the ANSES report [5] shows that HQs for the developmental effects of most potent PAHs (benzo[a]pyrene and dibenzo[a,h]anthracene) detected in diapers reach values higher than 50 while cancer risks estimates reach values exceeding $10^{-3}$. Even when adjusting the intake from diapers for the rewet factor of 1\% (Table 4), levels of cancer risks remain totally unacceptable, especially when cumulated over three years of diaper use. These estimates rely on the assumption that dermally-absorbed PAHs can cause systemic cancers as observed in animals with chronic oral exposure. This assumption, however, is strongly challenged by animal studies showing that PAHs applied dermally induce only skin tumours. Logically thus, cancer risk estimates should be calculated not with the oral but with the dermal CSF. Estimates of skin cancer risks of PAHs calculated with the dermal CSF of $3.5\left(\mu \mathrm{g} / \mathrm{cm}^{2} / \text { day) }\right)^{-1}$ proposed by Knafa et al. [8] are shown in Table 5 . Even when incorporating the rewet factor of $1 \%$, these estimates are even higher than those based on the oral CSF.

Table 4. Risk assessment of polycyclic aromatic hydrocarbons (PAHs) in diapers with the scenario 2.1 equation incorporating a rewet factor of $1 \%$ and comparison of the intake from diapers with that from breast milk.

\begin{tabular}{|c|c|c|c|c|c|c|c|c|c|c|}
\hline HAPs & $\begin{array}{c}\text { Concentration } \\
(\propto \mathrm{g} / \mathrm{kg})^{1}\end{array}$ & $\begin{array}{c}\text { Intake } \\
\text { from diaper } \\
(\propto \mathrm{g} / \mathrm{kg} / \mathrm{d})^{2}\end{array}$ & $\mathrm{TEF}^{3}$ & $\begin{array}{c}\text { Intake from } \\
\text { diaper } \\
(\propto g \mathrm{TEQ} / \mathrm{kg} / \mathrm{d})^{2}\end{array}$ & $\begin{array}{c}\text { EPA } \\
\text { oral RfD. } \\
(\propto \mathrm{g} / \mathrm{kg} / \mathrm{d})\end{array}$ & $\begin{array}{c}\text { Hazard } \\
\text { quotient }\end{array}$ & $\begin{array}{c}\text { EPA } \\
\text { oral CSF } \\
(\mathrm{mg} / \mathrm{kg} / \mathrm{d}) \\
\end{array}$ & $\begin{array}{c}\text { Excesss } \\
\text { cancer } \\
\text { risk }\end{array}$ & $\begin{array}{c}\text { Intake from } \\
\text { breast milk } \\
(\circ \mathrm{g} / \mathrm{kg} / \mathrm{d})^{4}\end{array}$ & $\begin{array}{c}\text { Intake ratio } \\
\text { breast } \\
\text { milk/diaper }\end{array}$ \\
\hline Cyclopenta[c,d]pyrene & 311 & 0.15 & 0.1 & 0.015 & & 0.05 & & $1.09 \times 10^{-6}$ & & \\
\hline Chrysene & 249 & 0.12 & 0.01 & 0.0012 & & 0.004 & & $8.76 \times 10^{-8}$ & 0.12 & 1.0 \\
\hline 5-methylchrysene & 311 & 0.15 & 0.01 & 0.0015 & & 0.005 & & $1.09 \times 10^{-7}$ & & \\
\hline Benzo[b]fluoranthene & 381 & 0.19 & 0.1 & 0.019 & & 0.063 & & $1.34 \times 10^{-6}$ & 0.11 & 0.58 \\
\hline Benzo[k]fluoranthene & 369 & 0.18 & 0.1 & 0.018 & 0.3 & 0.06 & 1 & $1.29 \times 10^{-6}$ & 0.88 & 4.89 \\
\hline Benzo[j]fluoranthene & 369 & 0.18 & 0.1 & 0.018 & & 0.06 & & $1.29 \times 10^{-6}$ & & \\
\hline Benzo[e]pyrene & 598 & 0.29 & 0.01 & 0.0029 & & 0.0097 & & $2.10 \times 10^{-7}$ & & \\
\hline Benzo[a]pyrene & 405 & 0.20 & 1 & 0.11 & & 0.67 & & $1.42 \times 10^{-5}$ & 0.11 & 0.55 \\
\hline Dibenzo[a,h]anthracene & 311 & 0.15 & 1 & 0.15 & & 0.50 & & $1.09 \times 10^{-5}$ & 0.61 & 4.07 \\
\hline Benzo[g,h,i]perylene & 418 & 0.21 & 0.01 & 0.0021 & & 0.007 & & $1.47 \times 10^{-7}$ & 0.73 & 3.48 \\
\hline $\mathrm{PAHs}$ & 3,722 & 1.82 & & 0.34 & & 1.13 & & $2.41 \times 10^{-5}$ & 2.56 & 1.41 \\
\hline 8PAHs & 2,133 & 1.05 & & & & & & & 2.56 & 2.44 \\
\hline 4PAHs & 1,035 & 0.51 & & & & & & & 0.34 & 0.67 \\
\hline
\end{tabular}

${ }^{1}$ Extraction from whole diaper with synthetic urine (ANSES scenario 2.2).

${ }^{2}$ Intake from diaper was calculated according to the scenario 2.1 equation incoporating a rewet factor of $1 \%$ for an infant aged 0-6 months (body weight, $3.9 \mathrm{~kg}$; 7.98 diapers/day; diaper weight, $24 \mathrm{~g}$; rewet factor, 1\%).

${ }^{3}$ ANSES used the TEF values proposed by INERIS [32].

${ }^{4}$ Intake from breast milk was based on the data of Santonicola et al. [33] and calculated for an infant of $5 \mathrm{~kg}$ of body weight fed daily with $700 \mathrm{ml}$ of brest milk containing $25 \mathrm{~g} / \mathrm{l}$ of lipids. 
Table 5. Risk of skin cancer from polycyclic aromatic hydrocarbons (PAHs) in diapers assessed by the ANSES or the EDANA equation using a dermal cancer slope factor (CSF) of $3.5\left(\mu \mathrm{g} / \mathrm{cm}^{2} / \text { day }\right)^{-1}$.

\begin{tabular}{|c|c|c|c|c|c|c|c|}
\hline PAHs & $\begin{array}{c}\text { Concentration } \\
(\circ \mathrm{g} / \mathrm{kg})^{1} \\
\end{array}$ & $\begin{array}{c}\text { Intake from } \\
\text { diaper }^{2} \\
(\circ g / d)\end{array}$ & $\mathrm{TEF}^{3}$ & $\begin{array}{c}\text { Intake from } \\
\text { diaper }^{2} \\
\text { (og TEQ/d) }\end{array}$ & $\begin{array}{c}\text { Intake from } \\
\text { diaper } \\
\left(\mathrm{og} / \mathrm{cm}^{2} / \mathrm{d}\right)\end{array}$ & $\begin{array}{c}\text { Dermal } \\
\mathrm{CSF}^{5} \\
\left(\propto \mathrm{g} / \mathrm{cm}^{2} / \mathrm{d}\right)^{-1} \\
\end{array}$ & $\begin{array}{c}\text { Excesss } \\
\text { skin cancer } \\
\text { risk } \\
\end{array}$ \\
\hline \multicolumn{8}{|c|}{ Intake calculated according to the scenario 2.2} \\
\hline Cyclopenta[c,d]pyrene & 311 & 59.6 & 0.1 & 5.96 & $2.55 \times 10^{-2}$ & & $6.36 \times 10^{-3}$ \\
\hline Chrysene & 249 & 47.7 & 0.01 & 0.48 & $2.04 \times 10^{-3}$ & & $5.09 \times 10^{-4}$ \\
\hline 5-methylchrysene & 311 & 59.6 & 0.01 & 0.6 & $2.55 \times 10^{-3}$ & & $6.36 \times 10^{-4}$ \\
\hline Benzo[b]fluoranthene & 381 & 73.0 & 0.1 & 7.3 & $3.12 \times 10^{-2}$ & & $7.79 \times 10^{-3}$ \\
\hline Benzo[k]fluoranthene & 369 & 70.7 & 0.1 & 7.1 & $3.02 \times 10^{-2}$ & & $7.55 \times 10^{-3}$ \\
\hline Benzo[j]fluoranthene & 369 & 70.7 & 0.1 & 7.1 & $3.02 \times 10^{-2}$ & 3.5 & $7.55 \times 10^{-3}$ \\
\hline Benzo[e]pyrene & 598 & 114.6 & 0.01 & 1.15 & $4.89 \times 10^{-3}$ & & $1.22 \times 10^{-3}$ \\
\hline Benzo[a]pyrene & 405 & 77.6 & 1 & 77.6 & $3.31 \times 10^{-1}$ & & $8.28 \times 10^{-2}$ \\
\hline $\operatorname{Dibenzo}[\mathrm{a}, \mathrm{h}]$ anthracene & 311 & 59.6 & 1 & 59.6 & $2.55 \times 10^{-1}$ & & $6.36 \times 10^{-2}$ \\
\hline Benzo[g,h,i]perylene & 418 & 80 & 0.01 & 0.80 & $3.42 \times 10^{-3}$ & & $8.55 \times 10^{-4}$ \\
\hline PAHs & 3,722 & 713 & & 168 & $7.16 \times 10^{-1}$ & & $1.79 \times 10^{-1}$ \\
\hline \multicolumn{8}{|c|}{ Intake calculated according to the scenario 2.1 equation (rewet factor of $1 \%$ ) } \\
\hline Cyclopenta[c,d]pyrene & 311 & 0.6 & 0.1 & 0.060 & $2.55 \times 10^{-4}$ & & $10^{-5}$ \\
\hline Chrysene & 249 & 0.48 & 0.01 & 0.0048 & $2.04 \times 10^{-5}$ & & $5.09 \times 10^{-6}$ \\
\hline 5-methylchrysene & 311 & 0.6 & 0.01 & 0.0060 & $2.55 \times 10^{-4}$ & & $6.36 \times 10^{-6}$ \\
\hline Benzo[b]fluoranthene & 381 & 0.73 & 0.1 & 0.073 & $3.12 \times 10^{-4}$ & & $7.79 \times 10^{-5}$ \\
\hline Benzo[k]fluoranthene & 369 & 0.71 & 0.1 & 0.071 & $3.02 \times 10^{-4}$ & & $7.55 \times 10^{-5}$ \\
\hline Benzo[j]fluoranthene & 369 & 0.71 & 0.1 & 0.071 & $3.02 \times 10^{-4}$ & 3.5 & $7.55 \times 10^{-5}$ \\
\hline Benzo[e]pyrene & 598 & 1.15 & 0.01 & 0.012 & $4.89 \times 10^{-5}$ & & $1.22 \times 10^{-5}$ \\
\hline Benzo[a]pyrene & 405 & 0.78 & 1.0 & 0.78 & $3.32 \times 10^{-3}$ & & $8.28 \times 10^{-4}$ \\
\hline Dibenzo[a,h]anthracene & 311 & 0.6 & 1.0 & 0.60 & $2.55 \times 10^{-3}$ & & $6.36 \times 10^{-4}$ \\
\hline Benzo[g,h,i]perylene & 418 & 0.8 & 0.01 & 0.080 & $3.42 \times 10^{-5}$ & & $8.55 \times 10^{-6}$ \\
\hline PAHs & 3,722 & 7.13 & & 1.68 & $7.16 \times 10^{-3}$ & & $1.79 \times 10^{-3}$ \\
\hline
\end{tabular}

${ }^{1}$ Extraction from whole diaper with synthetic urine (ANSES scenario 2.2).

${ }^{2}$ Intake from diaper calculated for an infant aged 0-6 months (body weight, $3.9 \mathrm{~kg}$; 7.98 diapers/day; diaper weight, $24 \mathrm{~g}$ )

${ }^{3}$ ANSES used the TEF values proposed by INERIS [32].

${ }^{4}$ Intake based on a skin surface area in contact with diaper of $234 \mathrm{~cm}^{2}$ [11,12].

${ }^{5}$ Dermal cancer slope factor of benzo[a]pyrene from Knafla et al. [10].

It is of course inconceivable that diapers could be contaminated by PAHs at levels entailing cancer risks comparable to those observed in the industry, even in industries not complying with the maximal risk level for occupational exposure set by the European Commission $\left(10^{-4}\right)$ [36]. These unrealistic estimates cannot be explained by the TEF approach adopted by ANSES that EFSA considers scientifically not valid because of lack of data for the oral carcinogenicity of individual PAHs [13]. As shown in Table 6, the alternative margin of exposure (MOE) approach used by EFSA for assessing risks of PAHs in food products leads also to totally unacceptable risks. The MOE calculated with the EDANA equation (rewet factor of $1 \%$ ) for the intake of benzo[a]pyrene (MOE, 342) and of the 8 PAHs carcinogenic in animals (MOE, 471) are largely below acceptable levels (MOE 
of at least 10,000 according to EFSA). Alone, the overly conservative assumptions made in the ANSES report also cannot explain risks of that magnitude. The only possible explanation lies in the combined use of the overconservative scenario 2.2 and of the LOQ/2 values of an inadequate analytical method as surrogate concentrations in diapers. The survey conducted in 2019 by the Swiss Federal Food Safety and Veterinary Office suggests that values of PAHs in diapers used by ANSES have been overestimated by 2 to 3 orders of magnitude [31].

Table 6. Margin of exposure (MOE) for polycyclic aromatic hydrocarbons (PAHs) from diapers calculated according to scenario 2.2 equation or the scenario 2.1 equation incorporating the rewet factor of $1 \%$.

\begin{tabular}{|c|c|c|c|c|}
\hline PAHs & $\begin{array}{c}\text { Intake from } \\
\text { diaper } \\
(\circ \mathrm{cg} / \mathrm{kg} / \mathrm{d})^{1} \\
\end{array}$ & $\begin{array}{l}\text { BMDL10 } \\
(\mathrm{mg} / \mathrm{kg} / \mathrm{d})^{2} \\
\end{array}$ & MOE & $\begin{array}{c}\text { MOE } \\
\text { (1\% rewet factor) }\end{array}$ \\
\hline $\mathrm{BaP}$ & 19.9 & 0.07 & 3.52 & 352 \\
\hline PAH4 & 50.8 & 0.34 & 6.69 & 669 \\
\hline PAH8 & 104 & 0.49 & 4.71 & 471 \\
\hline
\end{tabular}

${ }^{1}$ Extraction from whole diaper with synthetic urine (scenario 2.2). Intake from diaper calculated for an infant aged 0-6 months (body weight, $3.9 \mathrm{~kg}$; 7.98 diapers/day; diaper weight, $24 \mathrm{~g}$ )

${ }^{2}$ From EFSA [13]

Two lines of evidence add support to the view that the ANSES report has unreasonably overestimated cancer risks of PAHs in diapers. The first comes from the comparison of PAHs intake from diapers with that from human milk, a comparison made possible if one assumes, as does ANSES, that PAHs cause systemic cancers irrespective of the route of exposure. When incorporating the rewet factor of $1 \%$, the intake of PAHs from diapers is rather similar to that from human milk (Table 4). However, if concentrations of PAHs have been overestimated by more than two orders of magnitude as suggested by data from Switzerland [31], the intake from mother milk should be more than 100 times greater than that from diapers. There is no epidemiological evidence whatsoever associating breastfeeding with increased risks of cancer or developmental effects. On the contrary, breastfeeding is unanimously recognized as protective against various diseases including cancers (leukaemia) and as beneficial to the child's neurodevelopment, improving the IQ and reducing the risk of behavioural disorders $[37,38]$.

The second line of evidence comes from epidemiological or case-report studies that provide no indication at all of adverse effects of diapers despite decades of use by almost all children of wealthy countries. Would diapers pose cancer risks as high as $10^{-3}$ as suggested by the ANSES report, it is hard to believe that such risks could have passed undetected after such a long and widespread use as the large-scale use of disposable diapers started in the USA in 1961 [39]. In the anogenital region, the highly permeable scrotum has long been known to be particularly sensitive to the carcinogenic effects of PAHs. The squamous cell carcinoma (SCC) is the type of scrotal malignancy caused by occupational exposure specifically to PAHs. With preventive measures implemented at workplace, SCC has become a very rare cancer with a steady incidence rate through the $20^{\text {th }}$ century. The main non-occupational risk factors of SCC are sun exposure, the human papilloma virus and several types of treatment for skin diseases. As the median range at diagnosis is 52-57 years, it appears unlikely that SCC could be initiated during infancy, even if the median SCC latency is close to 30 years [40]. 


\section{Other compounds present in diapers at potentially unsafe levels according to ANSES}

Table 7 presents the ANSES risk assessment for substances that exceeded HRVs during the first year of life only (HICC, hydroxy isohexyl cyclohexene carboxaldehyde; BPMP, butyl phenyl methyl propional) or for which there was a risk of HRVs exceedance when aggregating exposure from diapers with that from other sources (the other compounds in Table 7). In the ANSES report, this included also the hexachlorobenzene pesticide and 1,2,4-trichlorobenzene but the presence of these compounds in the list was due to calculation errors by ANSES (the daily intakes per $\mathrm{kg}$ body weight instead of decreasing were increasing with child's age). Except for formaldehyde, these substances were detected in the extraction scenario 1 (with organic solvent) and they were not found in scenarios 2.1 and 2.2. The risk assessment in Table 7 is flawed by two major failures. First, like for PAHs, fragrance chemicals were not measured with an adequate analytical method and therefore ANSES based again its risk assessment on LOQ values, which are poor proxy of the effective exposure. Second, ANSES experts seem to have overlooked that the stratum corneum of the skin is primarily a physiological barrier that only lipophilic and uncharged molecules can easily cross. Obviously, several of the substances listed in Table 7 are too poorly absorbed across the skin to reasonably assume a fractional absorption of $100 \%$. This is particularly true for formaldehyde which is too reactive and too rapidly metabolized in the skin to be available systematically, especially at the very low concentrations found in diapers [41-43]. Applied dermally, formaldehyde reacts instantaneously with skin constituents to form a variety of derivatives including adducts and cross-links. This local reactivity is also reflected by the skin sensitizing properties of formaldehyde and the development of contact dermatitis in humans. Formaldehyde is also rapidly metabolized in the skin, which further reduces the systemic availability of unreacted formaldehyde. But even assuming that a small fraction of formaldehyde in diapers is dermally absorbed, the amount distributed to the body would be totally insignificant compared to that produced endogenously. Formaldehyde is, indeed, an intermediary metabolite essential to all cells with an endogenous daily turnover in humans estimated between $878-1.310 \mathrm{mg} / \mathrm{kg}$ bw [44]. Among the fragrances, D-limonene and benzyl salicylate are also poorly absorbed by the human skin while HICC and BPMP penetrate only to a limited extent [47-48].

Table 7. Risk assessment conducted by ANSES for other compounds detected or quantified in diapers at potentially unsafe levels.

\begin{tabular}{|c|c|c|c|c|c|c|c|c|}
\hline Compound & $\begin{array}{c}\text { Cooncentration } \\
(\mathrm{mg} / \mathrm{kg})^{1}\end{array}$ & $\begin{array}{c}\text { Intake } \\
\text { from diaper } \\
(\mathrm{mg} / \mathrm{kg} / \mathrm{d})^{2}\end{array}$ & $\begin{array}{c}\text { TDI } \\
(\mathrm{mg} / \mathrm{kg} / \mathrm{d}) \\
\end{array}$ & $\begin{array}{c}\text { Hazard } \\
\text { quotient }\end{array}$ & $\begin{array}{l}\text { NOAEL } \\
(\mathrm{mg} / \mathrm{kg} / \mathrm{d})\end{array}$ & MOE & $\mathrm{MOE}_{\mathrm{ref}}$ & $\begin{array}{c}\mathrm{MOE}_{\mathrm{ref}} / \\
\mathrm{MOE}\end{array}$ \\
\hline $1,2,3$ trichlorobenzene & 0.25 & $8.59 \times 10^{-4}$ & $8 \times 10^{-3}$ & 0.107 & & & & \\
\hline Coumarin & 25 & $8.59 \times 10^{-2}$ & 0.1 & 0.86 & & & & \\
\hline Limonene & 25 & $8.59 \times 10^{-2}$ & 0.1 & 0.86 & & & & \\
\hline Benzyl salicylate & 25 & $8.59 \times 10^{-2}$ & & & 50 & 582 & 100 & 0.17 \\
\hline HICC (Lyral®) & 25 & $8.59 \times 10^{-2}$ & & & 15 & 175 & 300 & 1.71 \\
\hline BPMP (Lilial $\left.{ }^{\circledR}\right)$ & 25 & $8.59 \times 10^{-2}$ & & & 5 & 58.2 & 100 & 1.72 \\
\hline Alpha-isomethyl ionone & 25 & $8.59 \times 10^{-2}$ & & & 50 & 582 & 100 & 0.17 \\
\hline Formaldehyde & 37.4 & 0.13 & 0.15 & 0.86 & & & & \\
\hline Formaldehyde (synthetic urine) & 2.75 & 0.135 & 0.15 & 0.90 & & & & \\
\hline
\end{tabular}

${ }^{1}$ Extraction from shredded diapers with organic solvent (scenario 1). Formaldehyde was alsoquantified in the extract of shredded diaper with synthetic urine (scenario 2.2). The value of $25 \mathrm{mg} / \mathrm{kgfor}$ the fragrances corresponds to the LOQ/2.

${ }^{2}$ Intake from diaper calculated according to the ANSES extraction scenario 1 (also ANSES extraction scenario 2.2 forformaldehyde) for an infant aged 0-6 months (body weight, $3.9 \mathrm{~kg}$; 7.98 diapers/day; diaper weight, $24 \mathrm{~g}$ )Abbreviations: 
HICC, hydroxy isohexyl cyclohexene carboxaldehyde; BMP, butyl phenyl methyl propional; TDI, tolerabledaily intake; MOE, margin of exposure; NOAEL, no-observed-adverse effect level.

For a meaningful assessment of the systemic effects of substances in Table 7, it is thus a prerequisite to adjust the daily intake for the dermal absorption while adjusting also HRVs for the oral absorption to properly compare the systemic doses. As shown in Table 8 , these adjustments for the effective absorption result in HQ values largely below 0.1 for limonene and formaldehyde and in a MOE for benzyl salicylate higher than 10,000. Values of HQ and of the MOEref/MOE for other compounds in Table 8 are between 0.1 and 1, which according to ANSES might not be sufficiently protective. Because these fragrances are added voluntarily and can be easily removed, ANSES decided not include them in its restriction proposal. Only formaldehyde was included with a concentration limit of 0.21 $\mathrm{mg} / \mathrm{kg}$ diaper [6]. It should be noticed that intakes from diapers of compounds in Table 7 and 8 were calculated with the scenario 1 equation incorporating a skin transfer factor of $7 \%$ (except for formaldehyde in the synthetic urine extract). If one replaces this transfer factor by the rewet factor of $1 \%$ recommended by Dey et al. [2], HQ values are further reduced and the MOE further increased by a factor of 7 , which makes systemic effects unlikely for all chemicals in Tables 7 and 8.

Table 8. Risk assessment of other compounds detected or quantified in diapers at potentially unsafe levels according to ANSES by taking into account the fractional dermal and oral absorption.

\begin{tabular}{|c|c|c|c|c|c|c|c|c|c|}
\hline Compound & $\begin{array}{l}\text { Cooncentration } \\
(\mathrm{mg} / \mathrm{kg})^{1}\end{array}$ & $\begin{array}{c}\text { Dermal } \\
\text { absorption } \\
(\%)^{2}\end{array}$ & $\begin{array}{c}\text { Intake } \\
\text { from diaper } \\
(\mathrm{mg} / \mathrm{kg} / \mathrm{d})^{3}\end{array}$ & $\begin{array}{c}\text { TDI } \\
(\mathrm{mg} / \mathrm{kg} / \mathrm{d}) \\
4\end{array}$ & $\begin{array}{c}\text { Hazard } \\
\text { quotient }\end{array}$ & $\begin{array}{c}\text { NOAEL } \\
(\mathrm{mg} / \mathrm{kg} / \mathrm{d})^{4}\end{array}$ & MOE & $\mathrm{MOE}_{\text {ref }}$ & $\begin{array}{c}\mathrm{MOE}_{\mathrm{ret}} / \mathrm{MO} \\
\mathrm{E}\end{array}$ \\
\hline $1,2,3$ trichlorobenzene & 0.25 & 100 & $8.59 \times 10^{4}$ & $8 \times 10^{-3}$ & 0.107 & & & & \\
\hline Coumarin & 25 & 100 & $8.59 \times 10^{-2}$ & 0.1 & 0.86 & & & & \\
\hline Limonene & 25 & 0.16 & $1.37 \times 10^{4}$ & 0.1 & 3 & & & & \\
\hline Benzyl salicylate & 25 & 0.031 & $0.27 \times 10^{-4}$ & & & 50 & $10^{6}$ & 100 & $5.4 \times 10^{-5}$ \\
\hline HICC (Lyral $\left.{ }^{\circledR}\right)$ & 25 & 14.3 & $1.23 \times 10^{-2}$ & & & 7.5 & 610 & 300 & 0.49 \\
\hline BPMP (Lilial®) & 25 & 5.1 & $0.44 \times 10^{-2}$ & & & 2.5 & 568 & 100 & 0.18 \\
\hline Alpha-isomethyl ionone & 25 & 100 & $8.59 \times 10^{-2}$ & & & 25 & 291 & 100 & 0.34 \\
\hline Formaldehyde & 37.4 & 0.5 & $0.65 \times 10^{-3}$ & 0.075 & $0.87 \times 10^{-2}$ & & & & \\
\hline Formaldehyde (synthetic urine) & 2.75 & 0.5 & $0.70 \times 10^{-3}$ & 0.075 & $0.94 \times 10^{-2}$ & & & & \\
\hline
\end{tabular}

${ }^{1}$ Extraction from shredded diaper with organic solvent. Formaldehyde was also quantified in the extract of shredded diaper with synthetic urine. The value of $25 \mathrm{mg} / \mathrm{kg}$ for the fragrances corresponds to the LOQ/2.

${ }^{2}$ Limonene, human in vivo [45]; benzyl salicylate, human skin, in vitro, [46]; HICC, human skin, in vitro, [47]; BPMP, human skin in vitro [50]; formaldehyde, monkeys, in vivo [42,43].

${ }^{3}$ Intake from diaper calculated according to the ANSES extraction scenario 1 for an infant aged 0-6 months (body weight, $3.9 \mathrm{~kg}$; 7.98 diapers/day; diaper weight, $24 \mathrm{~g}$ ).

${ }^{4}$ NOAEL or TDI of HICC, BPMP, alpha-isomethyl ionone and formaldehyde were adjusted for a fractional oral absorption of $50 \%$. The fractional oral absorption of other compounds was assumed to be $100 \%$.

Abbreviations: HICC, hydroxy isohexyl cyclohexene carboxaldehyde; BPMP, butyl phenyl methyl propional; TDI, tolerable daily intake; MOE, margin of exposure; NOAEL, no-observed-adverse effect level. 


\section{Conclusions}

The quantitative health risk assessment conducted by ANSES is flawed by several scientifically unjustified risk assessment approaches and assumptions that have led to incredible risk estimates and to concentration limits in diapers hardly quantifiable by current analytical methods. Even if a very conservative approach is understandable given the vulnerability of infants, it is not reasonable to assume a fractional dermal absorption of $100 \%$ and to calculate systemic risks for substances like formaldehyde, which are very poorly absorbed by the skin. Similarly, assuming that all the substance present in diapers can enter in contact with the skin is not realistic in regard to the very low fraction of absorbed fluid rewetting the skin. ANSES based its risk assessment of PAHs on a route- and species-extrapolation and doing so the French agency fails to consider that dermally applied PAHs induce only skin tumours. The risk overestimation for PAHs is most likely due to the combined use of an overconservative exposure scenario and of the LOQ values of an inadequate analytical method as surrogate concentrations in diapers. There are also some doubts about the accuracy of dioxin and DL-PCBs concentrations that display illogical and atypical patterns of congeners. Under the scenario deemed most reliable by ANSES, the total TEQ activity in diapers was indeed predominantly contributed by PCB 126, a congener with questionable potency and uncertain association with decreased sperm count. There is thus a clear need to revisit the ANSES risk assessment by using more accurate exposure data, more toxicologically relevant endpoints and more realistic exposure scenarios. The revisited risk assessment should also evaluate the plausibility and likelihood of adverse effects of diapers by comparing the intake from diapers with that from breast milk, which offers numerous benefits to child's health despite much higher concentrations of dioxins, DL-PCBs and PAHs than those found in diapers.

Author Contributions: The author confirms sole responsibility for the following: study conception
and design, data collection, analysis and interpretation of results, and manuscript preparation. Funding: This critical review was supported by the International Disposables and Nonwovens Association (EDANA).

Data Availability Statement: Concentrations of chemical substances in diapers used in this review can be found in the ANSES report (in French) [5].

Acknowledgments: Alfred Bernard is Honorary Research Director of the National Fund for Scientific Research (Belgium). The Federal Food Safety and Veterinary Office in Switzerland is gratefully acknowledged for having provided data about the concentrations of PAHs in diapers.

Conflicts of Interest: The author declares no conflict of interest. The funder had no role in the design of the study; in the collection, analyses, or interpretation of data; in the writing of the manuscript, or in the decision to publish the results.

\section{References}

1. Russell, W.; Steele, M.D. Diaper care for happier and healthier babies. Clin. Paediatr.2014, 53, 7S-8S.

2. Dey, S.; Purdon, M.; Kirsch, T.; Helbich, H.M.; Kerr, K.; Li, L.; Zhou, S. Exposure factor considerations for safety evaluation of modern disposable diaper. Regul. Toxicol. Pharmacol. 2016, 81, 183-193.

3. DeVito, M.J.; Schecter, A. 2002. Exposure assessment to dioxins from the use of tampons and diapers. Environ. Health Perspect. 2002, 110, 23-28.

4. EDANA, 2021. International disposables and nonwoven association. Call for evidence on a possible restriction on PAHs, furans, dioxins, PCBs and formaldehyde in single-use babby nappies. Comments on Annex XV report. Ref. 3165. https://echa.europa.eu/fr/registry-of-restriction-intentions/-/dislist/details/0b0236e1840698d5

5. ANSES, 2019. Agence nationale de sécurité sanitaire de l'alimentation, l'environnement et du travail, France. Sécurité des couches pour bébé. Avis révisé. pp. 1-206.

https://www.anses.fr/fr/content/avis-révisé-et-rapport-de-lanses-relatif-à-la-sécurité-des-couches-pour-bébé 
6. ANSES, 2020. French Agency for food, occupational and environmental health and safety, dossier submitter. Annex xv restriction report with its annex. Hazardous chemicals in single-use baby diapers. pp. 1-85 (annex pp. 1-198). https://echa.europa.eu/fr/registry-of-restriction-intentions/-/dislist/details/0b0236e1840698d5

7. Colón, J.; Forbis-Stokes, A.A.; Deshusses, M.A. 2015 Anaerobic digestion of undiluted simulant human excreta for sanitation and energy recovery in less-developed countries. Energy Sustain. Dev. 2015, 29, 57-64.

8. U.S. EPA (U.S. Environmental Protection Agency). 2017. Toxicological review of benzo[a]pyrene. pp. 1-234. https://iris.epa.gov/static/pdfs/0136tr.pdf

9. Knafla, A.; Petrovic, S.; Richardson, M.; Campbell, J.; Rowat, C. Development and application of a skin cancer slope factor for exposures to benzo[a]pyrene in soil. 2011. Regul. Toxicol. Pharmacol. 2011, 59, 101-110.

10. Boniol, M.; Verriest, J.P.; Pedeux, R.; Doré, J.F. 2008. Proportion of skin surface area of children and young adults from 2 to 18 years old. J. Invest. Dermatol. 2008, 128, 461-464.

11. U.S. EPA (U.S. Environmental Protection Agency). 2011. Exposure Factors Handbook. Edition (Final). U.S. Environmental Protection Agency, Washington, DC. EPA/600/R-09/052F. https://cfpub.epa.gov/ncea/risk/recordisplay.cfm?deid=236252

12. EFSA (European Food Safety Authority). Polycyclic aromatic hydrocarbons in food. Scientific opinion of the panel on contaminants in the food chain. Risk for animal and human health related to the presence of dioxins and dioxin-like PCBs in feed and food. EFSA Journal 2008, 724, 1-114. https://www.efsa.europa.eu/fr/efsajournal/pub/724

13. EFSA (European Food Safety Authority). Risk for animal and human health related to the presence of dioxins and dioxin-like PCBs in feed and food. EFSA Journal $2018 \quad 16,5333$. https://www.efsa.europa.eu/en/efsajournal/pub/5333

14. Focant, J.F.; Fréry, N.; Bidondo, M.; Eppe, G.; Scholl, G.; Saoudi, A.; Oleko, A.; Vandentorren, S. Levels of polychlorinated dibenzo-p-dioxins, polychlorinated dibenzofurans and polychlorinated biphenyls in human milk from different regions of France. Sci. Total Environ. 2013, 452-453, 155-162.

15. Fång, J.; Nyberg, E.; Bignert, A.; Bergman Å. Temporal trends of polychlorinated dibenzo-p-dioxins and dibenzofurans and dioxin-like polychlorinated biphenyls in mothers' milk from Sweden, 1972-2011. Environ. Int. 2013, 60, 224-231.

16. ATSDR (Agency for Toxic Substances and Disease Registry). Toxicological profile for chlorinated dibenzo-pdioxins. 1998. pp. 1-678.

https://www.atsdr.cdc.gov/toxprofiles/tp104.pdf

17. ATSDR (Agency for Toxic Substances and Disease Registry). Addendum to the toxicological profile for chlorinated dibenzo-p-dioxins. 2012. pp. 1-179.

https://www.atsdr.cdc.gov/toxprofiles/cdds_addendum.pdf

18. Schecter, A.; Ryan, J.J.; Päpke, O. Decrease in levels and body burden of dioxins, dibenzofurans, PCBS, DDE, and HCB in blood and milk in a mother nursing twins over a thirty-eight months period. Chemosphere 1998, 37, 1807-1816.

19. Kerger, B.; Leung, H.; Scott, P.; Paustenbach, D.; Needham, L.; Patterson, D.; Gerthoux, P..; Mocarelli, P. Ageand concentration-dependent elimination half-life of 2,3,7,8-tetrachlorodibenzo-p-dioxin in Seveso children. Environ. Health Perspect. 2006, 114, 1596-1602.

20. Strapácová, S.; Brenerová, P.; Krcmár, P.; Anderssonb, P.; van Ede, K.; van Duursen, M.; van den Berg, M.; Vondráček, J.; Machala, M. Relative effective potencies of dioxin-like compounds in rodent and human lung cell models. Toxicology 2018, 404-405, 33-41. 
21. Van Ede, K.I.; van Duursen, M.B.; van den Berg, M. Evaluation of relative effective potencies (REPs) for dioxinlike compounds to derive systemic or human-specific TEFs to improve human risk assessment. Arch. Toxicol. 2016, 90, 1293-1305.

22. Van Duursen, M.B.M.; van Ede, K.I.; van den Berg, M. One TEF concept does not fit all: the case for human risk assessment of polychlorinated biphenyls. Curr. Opinion Toxicol. 2017, 2, 103-108.

23. U.S. EPA (U.S. Environmental Protection Agency). Reanalysis of key issues related to dioxin toxicity and response to NAS Comments. 2012. pp 1-1,521. https://cfpub.epa.gov/ncea/iris/iris_documents/documents/supdocs/dioxinv1sup.pdf

24. IARC (International Agency for Research on Cancer). IARC monographs on the evaluation of carcinogenic risks to humans. Volume 69. Polychlorinated dibenzo-para-dioxins and polychlorinated dibenzofurans, IARC, Lyon, France. 1997. pp. 1-656 https://monographs.iarc.who.int/wp-content/uploads/2018/06/mono69.pdf

25. Minguez-Alarcon, L.; Sergeyev, O.; Burns, J.S.; Williams, P.L.; Lee, M.; Korrick, S.A.; Smigulina, L.; Revich, B.: Hauser, R. A longitudinal study of peripubertal serum organochlorine concentrations and semen parameters in young men: the Russian Children's Study. Environ. Health Perspect. 2017, 125, 460-466.

26. Mocarelli, P.; Gerthoux, P.M.; Patterson Jr., D.G.; Milani, S.; Limonta, G.; Bertona, M. Dioxin exposure, from infancy through puberty, produces endocrine disruption and affects human semen quality. Environ. Health Perspect. 2008, 116, 70-77.

27. Bernard, A.; Nickmilder, M. Association of breastfeeding with higher serum inhibin B level at adolescence. JAMA Pediatr. 2013, 167, 869-870.

28. Levine, H., Jørgensen, N.; Martino-Andrade, A.; Mendiola, J.; Weksler-Derri, D.; Mindlis I.; Pinotti, R.; Swan, S.H. Temporal trends in sperm count: a systematic review and meta-regression analysis. Hum. Reprod. Update 2017, 23, 646-659.

29. INERIS (Institut National de l'Environnement Industriel et des Risques). Hydrocarbures aromatiques polycycliques (HAPs). Évaluation de la relation dose-réponse pour des effets cancérigènes : approche substance par substance (facteurs d'équivalence toxique - FET) et approche par mélanges. Évaluation de la relation dose-réponse pour des effets non cancérigènes: Valeurs Toxicologiques de Référence (VTR). 2003; pp. https://www.ineris.fr/fr/hydrocarbures-aromatiques-polycycliques-haps

30. Santonicola, S. ; De Felice, A. ; Cobellis, L. ; Passariello, N. ; Peluso, A. ; Murru, N., Ferrante, M.C. ; Mercogliano, R. Comparative study on the occurrence of polycyclic aromatic hydrocarbons in breast milk and infant formula and risk assessment. Chemosphere 2017, 175, 383-390.

31. FSWO (Federal Food Safety and Veterinary Office in Switzerland). 2019. Personal communication of Dr Vincent Dudler, risk evaluation division of FSWO, February 9, 2021.

32. U.S. EPA (U.S. Environmental Protection Agency). Toxicological Review of Benzo[a]pyrene. 2017. https://iris.epa.gov/static/pdfs/0136tr.pdf

33. ADSTR. Toxicological profile for polycyclic aromatic hydrocarbons. U.S. Department of health and human services Public Health Service. Agency for Toxic Substances and Disease Registry. 1995. https://www.atsdr.cdc.gov/toxprofiles/tp69.pdf

34. IARC (International Agency for Research on Cancer). IARC Monographs on the evaluation of carcinogenic risks to humans. Chemical agents and related occupations. 2012; 100F:1-599. https://publications.iarc.fr/BookAnd-Report-Series/Iarc-Monographs-On-The-Identification-Of-Carcinogenic-Hazards-To-Humans/ChemicalAgents-And-Related-Occupations-2012 
35. Bourgart, E.; Barbeau, D.; Marques, M.; Von Koschembahr, A.; Béal, D.; Persoons, R.; Leccia, M.T.; Douki, T.; Maitre, A. A realistic human skin model to study benzo[a]pyrene cutaneous absorption in order to determine the most relevant biomarker for carcinogenic exposure. Arch. Toxicol. 1999, 93, 81-93.

36. Petit, P.; Maìtre, A.; Persoons, R. ; Bicout D.J. 2019. Lung cancer risk assessment for workers exposed to polycyclic aromatic hydrocarbons in various industries. Environ. Internat. 2019, 124, 109-120.

37. Ip, S.; Chung, M.; Raman, G.; Chew, P; Magula, N.; DeVine, D.; Trikalinos, T.; Lau, J. Breastfeeding and maternal and infant health outcomes in developed countries. Evid. Rep. Technol. Assess. 2006, 153, 1-186.

38. Binns, C.; Lee, M.; Low, W.Y. The long-term public health benefits of breastfeeding. 2016. Asia Pac. J. Public Health. 2016, 28, 7-14.

39. Dyer, D. 2005. Seven decades of disposable diapers. A record of continuous innovation and expanding benefit. The Wintrop Group, Inc. on behalf of EDANA. http://www.edana.org/docs/default-source/absorbent-hygieneproducts/edana---seven-decades-of-diapers.pdf?sfvrsn=3e24da15 2

40. Vyas, R.; Zargar, H.; Di Trolio, R.; Di Lorenzo, G.; Autorino, R. Squamous cell carcinoma of the scrotum: a look beyond the chimneystacks. World J. Clin. Cases 2014, 16, 654-660.

41. Jeffcoat, A.R.; Chasalow, F.; Feldman, D.B. 1983. Disposition of [14C] formaldehyde after topical exposure to rats, guinea pigs, and monkeys. In: Gibson JE, ed. Formaldehyde toxicity. Washington, DC: Hemisphere Publishing Corporation, 1983; pp. 38-50.

42. ATSDR (Agency for Toxic Substances and Disease Registry). Toxicological profile for formaldehyde. 1999; pp. 1-498. https://www.atsdr.cdc.gov/toxprofiles/tp111.pdf

43. SCCS (Scientific Committee on Consumer Safety). Opinion on the safety of the use of formaldehyde in nail hardeners. European Commission, Luxembourg, 2014; pp. 1-100.

http://ec.europa.eu/health/scientific_committees/consumer_safety/index_en.htm

44. EFSA (European Food Safety Laboratory). Endogenous formaldehyde turnover in humans compared with exogenous contribution from food sources. The EFSA Journal 2014, 12, 3550. https://efsa.onlinelibrary.wiley.com/doi/epdf/10.2903/j.efsa.2014.3550

45. Api, A.; Ritacco, G.; Hawkins, D. The fate of dermally applied [14C] d-limonene in rats and humans. Int. J. Toxicol. 2013, 32, 130-135.

46. Belsito, D.; Bickers, D.; Bruze, M.; Calow, P.; Greim, H.; Hanifin, J.M. A toxicologic and dermatologic assessment of salicylates when used as fragrance ingredients. Food Chem. Toxicol. 2007, 45, S318-S361.

47. SCCS (Scientific Committee on Consumer Safety). Opinion on hydroxyisohexyl 3-cyclohexene carboxaldehyde (HICC). European Commission, Luxembourg, 2017; pp. 1-54. https://ec.europa.eu/health/scientific_committees/consumer_safety/docs/sccs_o_074.pdf

48. SCCS (Scientific Committee on Consumer Safety). Opinion on the safety of Butylphenyl methylpropional (pBMHCA) in cosmetic products. European Commission, Luxembourg, 2019; pp.1-68. https://ec.europa.eu/health/sites/default/files/scientific_committees/consumer_safety/docs/sccs_o_213.pdf

49. Jimbo, Y. Penetration of fragrance compounds through human epidermis. J. Dermatol. 1983, 10, 229-239. 